\begin{tabular}{|c|l|}
\hline Title & Olfactory Discriminating A bility of Lacustrine Sockeye and Masu Sal mon in V arious Freshwaters \\
\hline Author(s) & Sato, Koji; Shoji, Takayuki; Ueda, Hiroshi \\
\hline Citation & Zoological Science, 17(3), 313-317 \\
\hline Issue Date & 2000-04 \\
\hline Doc URL & http://hdl.handle.net/2115/32926 \\
\hline Rights & (c) 日本動物学会 /本文献の公開は著者の意思に基づくものである \\
\hline Type & article \\
\hline File Information & http_www.jstage.jst.go.pdf7(3)313.pdf \\
\hline
\end{tabular}

Instructions for use 


\title{
Olfactory Discriminating Ability of Lacustrine Sockeye and Masu Salmon in Various Freshwaters
}

\author{
Koji Sato ${ }^{1 \dagger}$, Takayuki Shoji ${ }^{2}$ and Hiroshi Ueda ${ }^{1 *}$ \\ ${ }^{1}$ Toya Lake Station for Environmental Biology, Faculty of Fisheries, Hokkaido University, \\ Abuta, Hokkaido 049-5723, Japan \\ ${ }^{2}$ Graduate School of Pharmaceutical Sciences, Hokkaido University, \\ Sapporo 060-0812, Japan
}

\begin{abstract}
In order to study the olfactory discriminating ability of lacustrine sockeye salmon (Oncorhynchus nerka) and masu salmon (O. masou), the integrated olfactory nerve response to various freshwaters was recorded by electrophysiological techniques. In both species independent of sex and gonadal maturity, each freshwater caused a different olfactory response. Source and effluent waters of the culture pond at Toya Lake Station (the source and culture pond waters) evoked the minimum and maximum response magnitude, respectively. In cross-adaptation experiments, the culture pond water abolished all secondary responses to other freshwaters, and no freshwater abolished the secondary response to the culture pond water. The concentration response study revealed that the minimum concentration (threshold) to induce response to the culture pond water after adaptation to Lake Toya water was between 0.1 and $1.0 \%$. The present study indicates that the olfactory organ of lacustrine salmonids may discriminate different intensities of various freshwater odors.
\end{abstract}

\section{INTRODUCTION}

It is generally hypothesized that adult salmon primarily use olfactory cues during their homing migration when they migrate from the coastal area to the natal river. Since the olfactory homing hypothesis was introduced by Hasler and Wisby (1951), the importance of olfactory function to the salmonid homing migration was reported by many behavioral studies (Hasler and Scholz, 1983; Stabell, 1992). The electrophysiological studies also reported the relationship between the olfactory bulbar response (EEG) to natal stream water and the homing behavior of salmonids (Hara et al., 1965; Ueda et al., 1967, 1971; Satou, 1974; Kaji et al., 1975, Ueda, 1985). These studies examined the magnitude of EEG or differences of frequency spectrum as the exclusive parameter. Although the maximum magnitude of EEG was used as the index of the response to the odor of natal stream water, these magnitude has been considered to be independent of the recognition of natal stream water (Hara, 1994).

Bodznick $(1975,1978 a)$ recorded the EEG responses and the single olfactory bulb unit response in juvenile sockeye salmon (Oncorhynchus nerka) indicating that these responses showed the different properties to natural water and amino

\footnotetext{
* Corresponding author: Tel. +81-142-75-2651; FAX. +81-142-75-2943.

E-mail. hueda@ccms1.hucc.hokudai.ac.jp ${ }^{\dagger}$ Present address: Division of Biological Sciences, Graduate School of Science, Hokkaido University, Sapporo 060-0810, Japan
}

acids. Nevitt et al. (1994) recorded the responses to phenyl ethyl alcohol (PEA) and amino acids from olfactory receptor neuron of coho salmon (O. kisutch) by means of patch-clamp technique and indicated that the olfactory receptor neurons isolated from PEA-exposed salmon showed higher sensitivity to PEA than non-exposed fish. However, few studies examined the response of primary olfactory neuron activity to various freshwaters.

In the present study, olfactory discriminating ability was examined in two lacustrine salmonids, sockeye salmon $(O$. nerka) and masu salmon (O. masou), whose habitat was freshwater throughout their life history. The integrated olfactory nerve response to various freshwaters was recorded as an index to the olfactory discrimination of various freshwater odors. Cross-adaptation experiments to two different kinds of freshwater as well as a concentration response analysis estimating minimum concentration (threshold) value were also carried out.

\section{MATERIALS AND METHODS}

\section{Experimental animals}

Lacustrine sockeye and masu salmon were used in this study. The sockeye salmon were obtained from two different sources; some fish were reared from eggs at Toya Lake Station for Environmental Biology, and some fish were caught in Lake Shikotsu during their homing migration. The latter fish were transferred to the station and maintained for one week in the outdoor culture pond supplied with a continuous flow of spring water. The gonadal maturity was estimated by gonadosomatic index (GSI: gonad weight/body weight $\times 100)$. They 
were divided into three groups; (1) mature fish from Lake Shikotsu (male: folk length (FL) $25.95 \pm 2.03 \mathrm{~cm}$, GSI 4.11 $\pm 1.36, \mathrm{n}=7$; female: FL 26.17 $\pm 0.55 \mathrm{~cm}$, GSI 13.32 $\pm 2.15, \mathrm{n}=6$ ), (2) mature female from Toya Lake Station (FL $31.22 \pm 4.72 \mathrm{~cm}$, GSI 11.09 $\pm 4.87, \mathrm{n}=4$ ), (3) immature female from Toya Lake Station (FL 25.22 $\pm 0.56 \mathrm{~cm}$, GSI $0.54 \pm 0.23, \mathrm{n}=5$ ). Two mature male masu salmon ( $\mathrm{FL} 22.75 \pm 0.07$ $\mathrm{cm}, \mathrm{GSI} 6.14 \pm 1.74$ ) and 6 immature male masu salmon (FL $21.66 \pm 1.37 \mathrm{~cm}, \mathrm{GSI} 0.85 \pm 0.32$ ) reared at Toya Lake Station were also used. The mature fish were tested from September to Novermber, 1995 and 1996, the immature fish were tested from April to June, 1996.

\section{Olfactory nerve response recording}

The integrated olfactory nerve response was recorded using the electorophysiological technique of Sveinsson and Hara (1990). The fish were immobilized with an intramuscular injection of gallamine triethiodide (Sigma, St. Louis, MO, USA; $3 \mathrm{mg} / \mathrm{kg}$ body weight) and locally anesthetized with lidocaine at the wound and head fixation points. The gills were perfused through the mouth with aerated solution containing tricaine-methane sulphate (MS 222, Sigma; $70 \mathrm{mg} / \mathrm{l}$ ) which was never in contact with the olfactory rosette. Exposed parts of the fish were covered with wet tissue and kept moist throughout the experiment. The skin and a part of skull were removed to expose the olfactory bulbs and the proximal part of olfactory nerve. The olfactory nerve responses were recorded from twin tungsten electrodes inserted in the olfactory nerve. A grand electrode filled with $3 \mathrm{M} \mathrm{KCl}-$ agar $(2 \%)$ bridged to an $\mathrm{Ag}-\mathrm{AgCl}$ electrode was placed lightly on the dorsal skin. Electrodes were not removed throughout the experiments. The signal was amplified by AC preamplifier (MOD. DAM-5A, W-P Instruments, Sarasota, FL, USA) with a bandpass of $300-3 \mathrm{KHz}$ and integrated by the hand-made electric integrator (time constant $=0.3$ s). Integrated olfactory nerve responses were recorded by a pen recorder.

\section{Olfactory stimulants}

The irrigating and stimulating solutions were applied to the olfactory epithelium through a stainless steel tube. Freshwaters used for stimulation were as follows: water from Lake Toya (lake water), source and effluent waters of the culture pond at Toya Lake Station (source and culture pond waters), and waters from River Poromoi and River Sobetsu (Poromoi and Sobetsu waters) that flow into Lake Toya. Effluent water from the Shikotsu Salmon Hatchery (hatchery water), which is the natal river for the sockeye salmon in Lake Shikotsu, was also applied. Each water was drew just before the experiments, the water temperature was left at room temperature, and was applied to the olfactory epithelium at a constant flow rate $(11 \mathrm{ml} / \mathrm{min})$. The magnitude of olfactory response was measured from the spontaneous level to the peak, and standardized to the response to $10^{-5} \mathrm{M} \mathrm{L}$-serine dissolved in distilled water. This amino acid was chosen because it consistently induces a large response in fish olfactory organ.

\section{Cross-adaptation experiment}

First, the olfactory epithelium was exposed to distilled water (DW) for $3 \mathrm{~min}$, then one freshwater was applied until the response was stabilized, then the other freshwater was applied, and finally DW was applied again.

\section{Statistics}

Data were expressed as mean \pm standard deviations or errors. Statistical analyses were calculated by two-way factorial analysis of variance (ANOVA) and Fisher's PLSD test.

\section{RESULTS}

Each freshwater produced a different magnitude of electrophysiological response that was recordable from the olfac- tory nerve in the lacustrine sockeye salmon (Fig. 1A) and masu salmon (Fig. 1B). In sockeye salmon reared at Toya Lake Station, the culture pond water and the hatchery water evoked the maximum response magnitude, and the source water elicited the minimum response magnitude, independent of gonadal maturity. The response to the lake water was lower than that to the Poromoi water. In masu salmon, the culture pond water also evoked the maximum response magnitude, regardless of gonadal maturity. In sockeye salmon caught
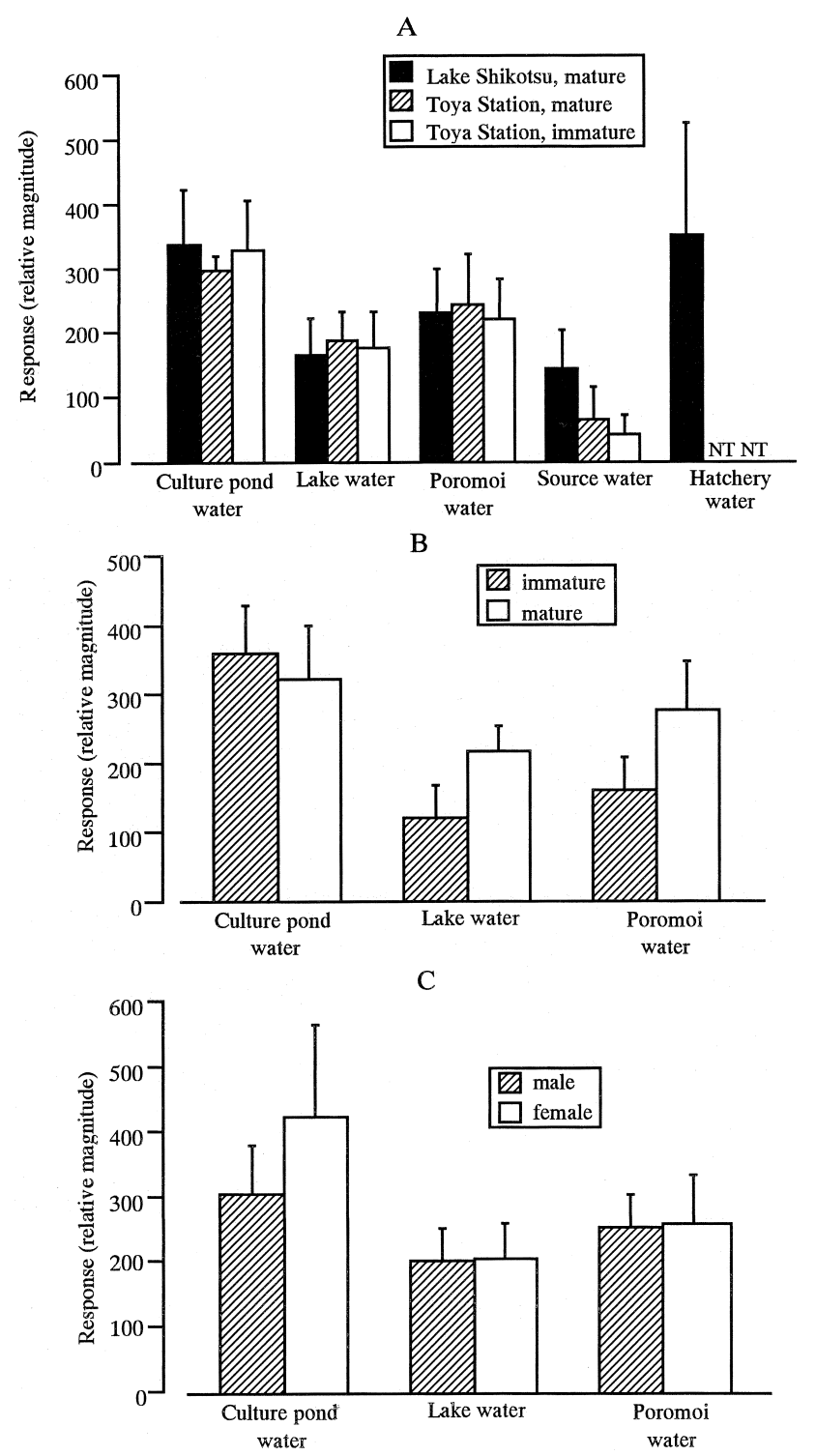

Fig. 1. Relative magnitude of integrated olfactory nerve responses to various freshwaters in sockeye salmon (A) and masu salmon (B). And comparison between male and female sockeye salmon caught in Lake Shikotsu (C). Magnitude of the response is expressed in \% of response to $10^{-5} \mathrm{M}$ L-serine dissolved in distilled water. In fish caught in Lake Shikotsu, there are significant differences between the culture pond water and other test waters $(n=13$, ANOVA: $p<0.0001$; Fisher's PLSD test: $p<0.05)$, and no significant differences between male and female $(p>0.05, n=13)$. Vertical bars represent standard deviations. NT; not tested. 
in Lake Shikotsu, significant differences were observed between two waters (the culture pond and hatchery) and other test waters $(n=13$, ANOVA: $p<0.0001$; Fisher's PLSD test: $p<0.05$ ), but no differences were detected between the culture pond water and the hatchery water. The magnitude of response to test waters was compared between male and female of sockeye salmon from Lake Shikotsu, and there were no significant differences among sex $(n=13$, Fisher's PLSD test: $p>0.05$, Fig. 1C).

Figure 2 shows the typical olfactory nerve response of mature female sockeye salmon $(A)$ and mature male masu salmon (B) reared at Toya Lake Station to various freshwaters in the cross-adaptation experiment. No differences in typical olfactory nerve response to freshwater were observed between sockeye and masu salmon. In the first application, responses did not decrease to the spontaneous level within 2 $\mathrm{min}$. The culture pond water abolished all secondary responses to other freshwaters in both sockeye and masu salmon, and no freshwaters abolished the secondary response to the culture pond water. The Poromoi water abolished the secondary response to the lake and Sobetsu waters.

The magnitude of olfactory responses to the culture pond and Poromoi waters was compared after acclimation to the lake water in sockeye salmon (Fig. 3). The responses to the culture pond water were greater than those to the Poromoi water. Mature and immature fish reared at the station showed a lower response magnitude than mature fish caught in Lake Shikotsu $(n=16$, Two-way ANOVA: $p=0.028,0.043)$.

Concentration response curves for the olfactory nerve responses to the culture pond water diluted with the lake water were examined in three immature sockeye and masu salmon from Toya Lake Station (Fig. 4). First, the olfactory epithelium was exposed to the lake water for $5 \mathrm{~min}$, then a concentration series of the culture pond water diluted with the lake water was applied and the secondary response was recorded. All tested sockeye salmon responded to $1 \%$ culture pond water, but in some fish there was no response to $0.1 \%$ culture pond water. Masu salmon did not respond to $0.1 \%$ culture pond water.
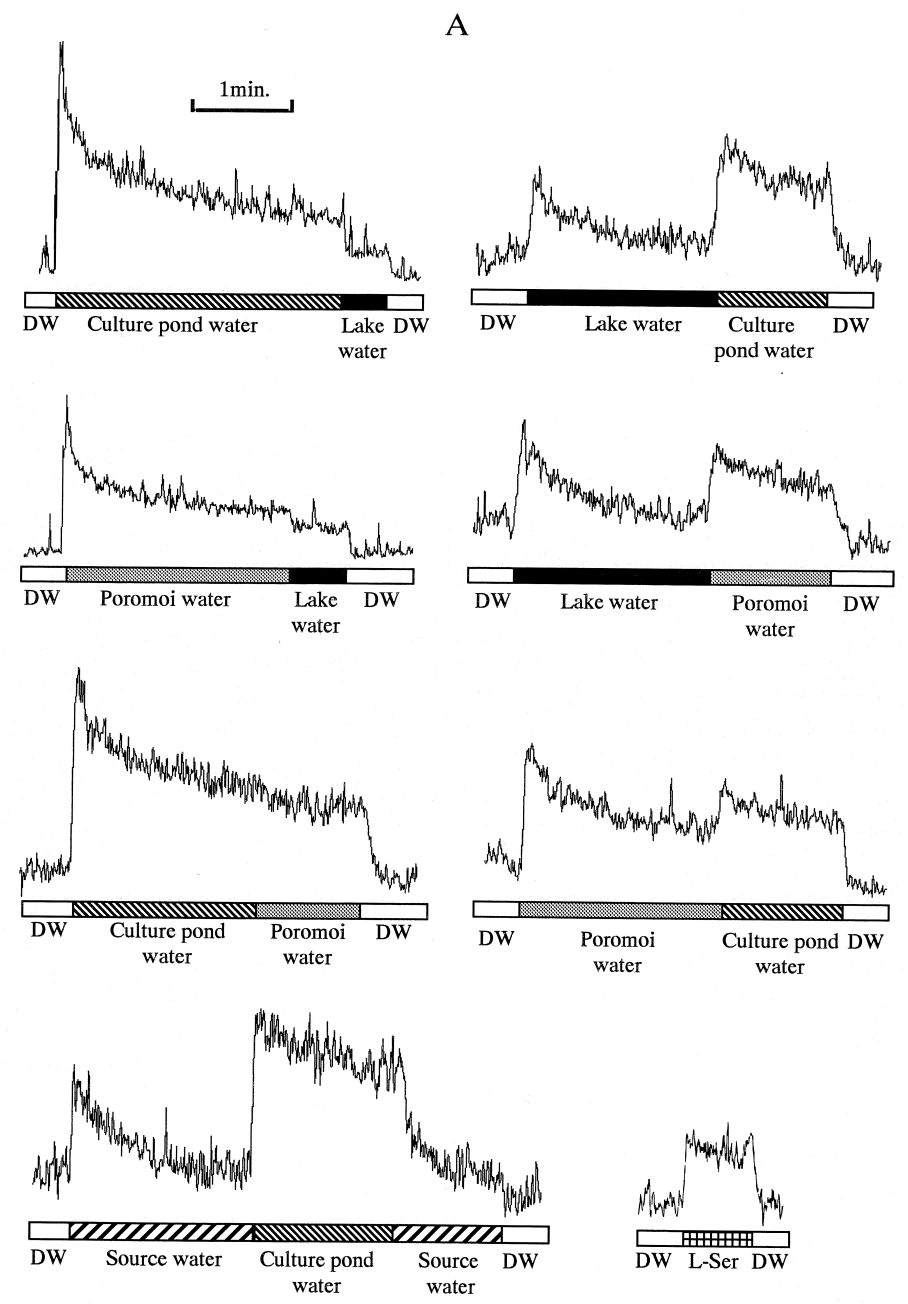

Fig. 2. Typical integrated olfactory nerve response in mature female sockeye salmon (A) and mature male masu salmon (B) reared at Toya Lake Station in the cross-acclimation experiments. The bar at the bottom of each record represents various freshwaters and the duration of stimulation. 


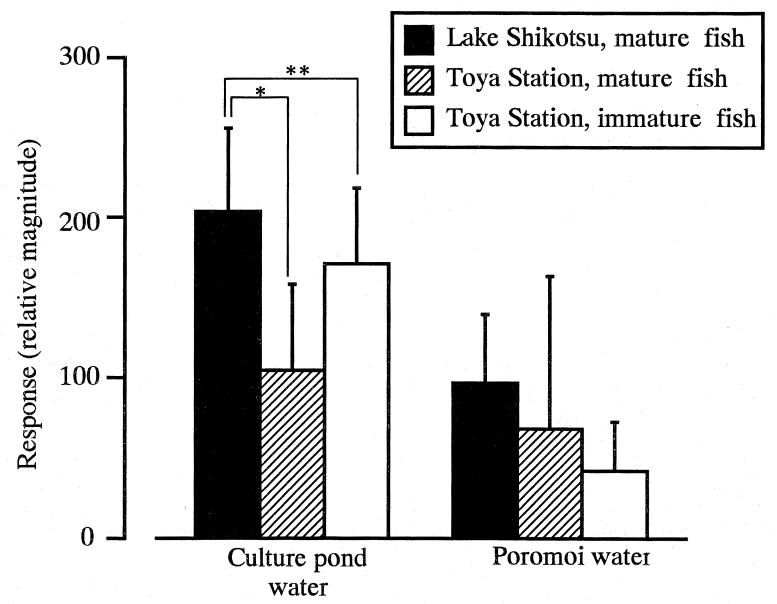

Fig. 3. Relative magnitude of integrated olfactory nerve responses to the culture pond and Poromoi waters after adaptation to the lake water in sockeye salmon. Magnitude of the response is expressed in $\%$ of response to $10^{-5} \mathrm{M} \mathrm{L}$-serine dissolved in distilled water. Significant differences $\left(n=16\right.$, Two-way Factorial ANOVA: ${ }^{*} p=0.028$, ${ }^{* *} p=0.043$ ) are found between fish caught in Lake Shikotsu and fish reared at Toya Lake Station. Vertical bars represent standard deviations.

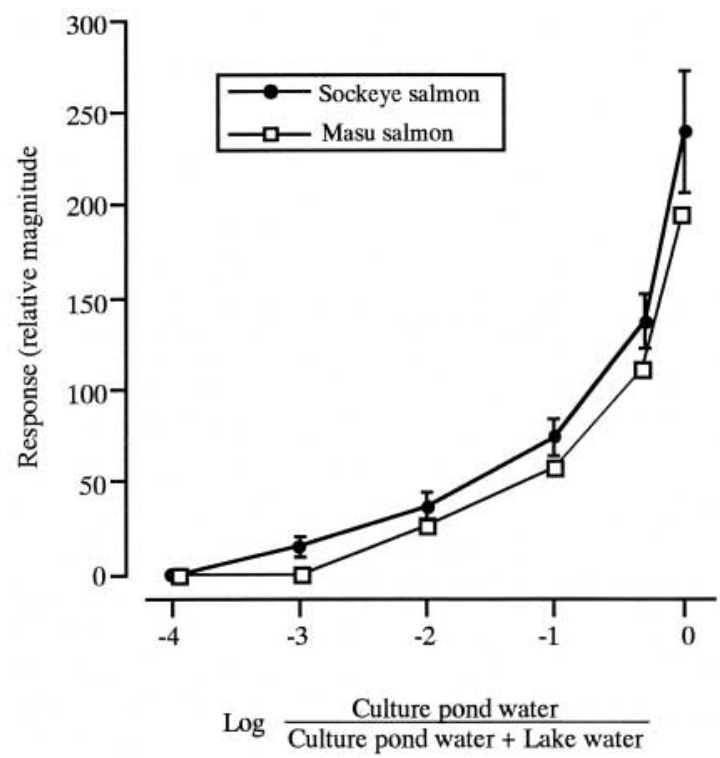

Fig. 4. Concentration response curves for the olfactory nerve responses in three immature female sockeye and immature male masu salmon reared at Toya Lake Station to the culture pond water diluted with the lake water demonstrating mean (symbols) and standard errors (vertical bars). Magnitude of the response is expressed in \% of response to $10^{-5} \mathrm{M} \mathrm{L}$-serine dissolved in distilled water.

\section{DISCUSSIONS}

The present study shows that the olfactory organs of lacustrine sockeye and masu salmon elicit different response properties to various freshwaters independent of sex and gonadal maturity. The relative magnitude of olfactory nerve responses in lacustrine salmonids suggests that each freshwater has different intensity of odors. Ueda et al. (1971) dem- onstrated that sockeye salmon were able to discriminate odor differences using olfactory bulbar response (EEG) recording methods. It was not clear, however, what kinds of odorants were discriminated by the olfactory system. By behavioral analyses, Idler et al. (1961) reported that natal river odors were volatile, heat-labile, neutral and dialyzable, while other studies proposed that the non-volatile fraction was important (Fagerlund et al., 1963; Bodznick, 1978b). Cooper et al. (1974) reported that the stimulatory portion of the natal river water was non-volatile by means of the recording EEG activities. Spectral analysis of EEG suggested that the home water stimulant(s) was absorbed on activated carbon and ionexchange resin, insoluble in petroleum-ether, dialyzable, nonvolatile, and heat-stable (Ueda, 1985). Chemicals which elicit the response from the olfactory receptor cells are amino acids, steroids, bile acids, and prostaglandins (Hara, 1994). The chemical composition of freshwater odorants that allow salmon to discriminate the natal river are now investigating in our laboratory, and our recent study suggests that amino acids are one of the important components for the determination of various freshwaters.

In chum salmon, lower-frequency components in EEG activity was important index for the recognition one of the stream as their home stream (Ueda, 1985). Nevitt et al. (1994) reported that the olfactory receptor cell responses of PEAexposed salmon were larger than those of non-exposed salmon suggesting that these cells have a high sensitivity to the natal river water odor. If olfactory receptor cells form the memory of the information related to the recognition of the home stream, the information of their natal river water should be reflected in the amplitude, in the frequency spectrum and/ or in the patterns of the response to home stream in the olfactory nerve. The response to a great variety of the odorants contained in natural waters may set off the fewer specific odor response in the response magnitude. Further studies are needed to characterize the nervous areas where the memory of natal river water odors is imprinted.

In sockeye salmon, the culture pond water elicited the largest olfactory response among various freshwaters. The fish reared at Toya Lake Station, however, showed less sensitivity to the culture pond and Poromoi waters than the fish caught in Lake Shikotsu when they were acclimated to the lake water. It is possible that some environmental factors and/ or genetic strain differences may affect the olfactory sensitivities. The olfactory systems of salmonids reared at Toya Lake Station may be adapted or acclimated to the culture pond water. Various odorants are thought to be released from fish, e.g. amino acids, steroids, and prostaglandins (Hara, 1994). Several studies have suggested that juvenile salmonids produce population-specific odors or pheromones which might be detectable by the adults during homing migration (Nørdeng, 1971, 1977; Groot et al., 1986; Quinn and Tolson, 1986). It has also been demonstrated that sex steroids and prostaglandins have effects on the olfactory epithelium of salmonids be acting as sexual pheromones (Moore and Scott, 1992; Moore and Warning, 1996). These odorants may modify the 
source water as to make the culture pond water more detectable to the olfactory system.

In both sockeye and masu salmon, the minimum concentration (threshold) to induce the olfactory nerve response to the culture pond water after adaptation to the lake water was between 0.1 and $1.0 \%$. This threshold level suggests that the olfactory discriminating ability of salmonids during homing migration must have a function within a limiting distance from the natal river. It has been discussed that sensory organs other than the olfactory organ are used by salmonids when they are migrating far from the natal river. Recently, we proposed that visual cues are important for orientation during homing migration in lacustrine sockeye salmon (Ueda et al., 1998).

In summary, the olfactory organs of lacustrine salmonids have an ablility to dicriminate different intensities of odors in various freshwaters. Of particular interest is the relation between this ability and the olfactory hypothesis on salmonid homing migration. The chemical characters of the natal river odorants which must be imprinted to the olfactory system of juvenile salmonids are presently unknown, and are now under investigation using the cross-adaptaion experiments in the lacustrine salmonids.

\section{ACKNOWLEDGMENTS}

We thank Professors Kohei Yamauchi and Kenzo Kurihara, Hokkaido University for their encouragement, staffs of the Toya Lake Station for their technical assistance, and Dr. Jill B.K. Leonard for her critical reading of the manuscript. This study was supported by grantin-aids from the Takeda Science Foundation, the Fisheries Agency, and the Ministry of Eduction, Science, Sports and Culture, Japan.

\section{REFERENCES}

Bodznick D (1975) The relationship of the olfactory EEG evoked by naturally-occurring stream waters to the homing behavior of sockeye salmon (Oncorhynchus nerka, Walbaum). Comp Biochem Physiol 52A: 487-495

Bodznick D (1978a) Characterization of olfactory bulb units of sockeye salmon with behaviorally relevant stimuli. J Comp Physiol 127: $147-155$

Bodznick D (1978b) Calcium ion: an odorant for natural water discriminations and the migratory behavior of sockeye salmon. J Comp Physiol 127: 157-166

Cooper JC, Lee GF, Dizon AE (1974) An evaluation of the use of the EEG technique to determine chemical constituents in homestream water. Wisc Acad Sci Arts Lett 62, 165-172

Fagerlund UHM, McBridge JR, Smith M, Tomlinson N (1963) Olfactory perception in migrating salmon III. Stimulants for adult sockeye salmon (Oncorhyncus nerka) in home stream waters. J Fish Res Bd Canada 20: 1457-1463

Groot C, Quinn TP, Hara TJ (1986) Responses of migrating adult sockeye salmon (Oncorhyncus nerka) to population-specific odors. Can J Zool 64: 926-932
Hara TJ (1994) The diversity of chemical stimulation in fish olfaction and gustation. Rev Fish Biol Fish 4: 1-35

Hara TJ, Ueda K and Gorbman A (1965) Electroencephalographic studies of homing salmon. Science 149: 884-885

Hasler AD, Scholz AT (1983) Olfactory imprinting and homing in salmon. Springer-Verlag, New York, PP 1-134

Hasler AD, Wisby WJ (1951) Discrimination of stream odors by fishes and relation to parent stream behavior. Am Naturalist 85: 223238.

Idler DR, McBridge JR, Smith M, Tomlinson N (1961) Olfactory perception in migrating salmon II. Studies on a laboratory bio-assay for homestream water and mammalian repellent. Can J Biochem Physiol 39: 1575-1584

Kaji S, Satou M, Kudo Y, Ueda K, Gorbman A (1975) Spectral analysis of olfactory responses of adult spawning chum salmon (Oncorhynchus keta) to stream waters. Comp Biochem Physiol 51A: 711-716

Moore A, Scott AP (1992) 17 $\alpha$, 20 $\beta$-dihydroxy-4-pregnen-3-one 20sulphate is a potent odorant precocious male Atlantic salmon (Salmo salar L.) parr which have been pre-exposed to the urine of ovulated females. Proc R Soc Lond, B249: 205-209

Moore A, Warning CP (1996) Electrophysiological and endorinological evidence that $F$-series prostaglandins function as priming pheromones in mature male Atlantic salmon (Salmo salar) parr. J Exp Biol 199: 2307-2316

Nevitt GA, Ditmann AH, Quinn TP, Moody WJ Jr (1994) Evidence for a peripheral olfactory memory in imprinted salomn. Proc Natl Acad Sci USA 91: 4288-4292

Nørdeng H (1971) Is the local orientation of anadromous fish determined by pheromones? Nature 233: 411-413

Nørdeng $H$ (1977) A pheromone hypothesis for homeward migration in anadromous salmonids. Oikos 28: 155-159

Quinn TP, Tolson GM (1986) Evidence of chemically mediated population recognition in coho salmon (Oncorhyncus kisutch). Can J Zool 64: 84-87

Satou M (1974) Electrical responses at various levels of the olfactory pathway in hime salmon, Oncorhynchus nerka. Jap J Physiol 24: 389-402

Stabell OB (1992) Olfactory control of homing behaviour in salmonids. In "Fish Chemoreception" Ed by TJ Hara, Chapman and Hall, Hants, pp 249-270

Sveisson T, Hara TJ (1990) Analysis of olfactory responses to amino acids in arctic char (Salvelinus alpinus) using a linear multiplereceptor model. Comp Biochem Physiol 97A: 279-287

Ueda H, Kaeriyama K, Mukasa k, Urano A, Kudo H, Shoji T, Tokumitsu Y, Yamauchi K, Kurihara K (1998) Lacustrine sockeye salmon return straightly to natal area from open water using both visual and olfactory cues. Chem Sense 23: 207-212

Ueda K (1985) An electrophysiological approach to the olfactory recognition of homestream waters in chum salmon. NOAA Tech Rep NMFS 27: 97-102

Ueda K, Hara TJ and Gorbman A (1967) Electroencephalographic studies on olfactory discrimination in adult spawning salmon. Comp Biochem Physiol 21: 133-143

Ueda K, Hara TJ, Satou M, Kaji S (1971) Electrophysiological studies of olfactory discrimination of natural waters by hime salmon, a land-locked Pacific salmon, Oncorhynchus nerka. J Fac Sci Univ Tokyo Sec IV 12: 167-182

(Received April 26, 1999 / Accepted October 29, 1999) 